\title{
2
}

\section{ANALISIS STRATEGI AKTUALISASI DIRI SASYA TRANGGONO PEREMPUAN PERUPA INDONESIA DALAM MASA PANDEMIK COVID-19}

IRA ADRIATI

Received: 7 Maret 2021; Accepted: 29 April 2021; Published: 30 Juni 2021

Ed. 2021; 4 (2): 224 - 230

\begin{abstract}
Sasya Tranggono is an Indonesian female artist who works with the subjects of puppets, flowers and butterflies. Her work is well known in the Indonesian art social scenes; she has actualized herself. In this research condition analyzes the self-actualization process during the Covid-19 pandemic. This research is a qualitative research. Using Abraham Maslow's theory of self-actualization which has been converted to fine arts, Hans Van Maneen's theory for the exhibition process, and Hennessy's theory relating to publication on social media. Based on the analysis, it can be seen that Sasya Tranggono tries to maintain her self-actualization even through social media such as Instagram and the web. She has collaborated with several galleries to exhibit her work online and offline. All of her publication strategies kept her at the pinnacle of self-actualization.
\end{abstract}

Keywords: Pandemik Covid-19, Aktualisasi Diri, Sasya Tranggono, daring, luring.

\section{PENDAHULUAN}

Pandemik covid-19 berpengaruh terhadap berbagai lini kehidupan manusia. Salah satunya adalah medan sosial seni rupa. Kondisi pandemik tidak memungkinkan galeri maupun museum mengadakan kegiatan pameran. Hal tersebut menyebabkan sulitnya seniman untuk mengaktualisasikan diri mereka. Komponen dalam medan sosial seni rupa seperti kurator, pemilik galeri, dan seniman kemudian mengalihkan pameran menjadi pameran secara online atau daring. Galeri dan seniman membuat ruang pamer secara virtual sehingga proses aktualisasi diri seniman maupun proses distribusi karya tetap berlangsung. Di samping itu diskusi-diskusi seni dilangsungkan dengan menggunakan aplikasi zoom maupun IG live (Instagram).
Dalam tulisan ini akan memfokuskan pada bagaimana proses aktualisasi diriyang dilakukan oleh Sasya Tranggono seorang perempuan seniman selama pandemic covid-19. Menarik untuk menganalisis bagaimana Sasya berusaha untuk tetap mempublikasikan karyanya walaupun selama pandemic dia tinggal di Singapore.

\section{METODOLOGI}

Dalam tulisan ini menggunakan metode manajemen seni dari Van Maneen khususnya berkaitan dengan penentuan tujuan kegiatan, teori aktualisasi diri dari Abraham Maslow, dan teori building your personal brand in the age of social media dari Brittany Hennessy. Teknik pengumpulan data menggunakan kaji pustaka untuk memperoleh data karya-karya Sasya 
Tranggono maupun untuk mengetahui ulasan-ulasan tentang karya Sasya yang telah ditulis. Observasi secara langsung dalam mengapresiasi karya Sasya telah dilakukan sebelum pandemic khususnya pada saat pameran tunggal di Galeri Nasional tahun 2018 maupun dalam kegiatan bedah buku di Galeri Sumardja tahun 2019.

\section{PERKEMBANGAN KARYA-KARYA SASYA TRANGGONO}

Sasya Tranggono merupakan perempuan perupa yang lahir pada tahun 1963 di Jakarta. Ia memulai belajar melukis setelah menyelesaikan pendidikan tinggi di bidang teknik. kemudian mengikuti workshop seni di the Vrije Academic Rotterdam, Belanda pada tahun 1995. Salah satu kemampuannya adalah melukis dengan media cat air di atas kanvas.

Subjectmatter karyanya pada periode awal adalah bunga. Bunga yang divisualisasikannya pada awalnya naturalis, selanjutnya Sasya mampu menjadikan bunga sebagai metafora dari emosinya. Apresiator tidak lagi terjebak pada bentuk bunga, melainkan diajak untuk mengembangkan imajinasi mereka agar masuk dalam emosi pelukisnya.

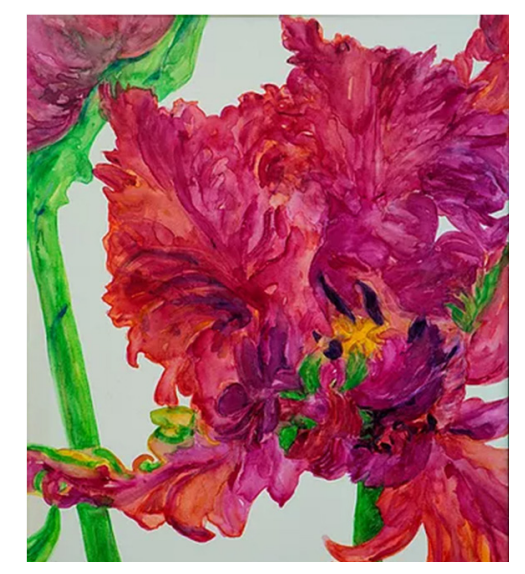

Gambar 1. Sasya Tranggono, "Love at First Sight”, 100x80cm, 2006 Sumber: https://www. Sasyatranggonostudio.com/
Tahap berikutnya Sasya memilih wayang golek yang menjadi subject matter dalam akryanya. Wayang golek tersebut seakan-akan mewakili berbagai perjalanan hidup seorang Sasya Tranggono. Wayang yang diambil dari seni tradisi di tangan Sasya menjadi sebuah ekspresi personalnya. Menjadi metafora untuk setiap fase dalam kehidupannya. Salah satunya bagaimana relasi dirinya dengan putra tunggalnya.

Periode wayang ini menjadi salah satu idiolect untuk Sasya. Wayang golek tersebut menjadi narasi untuk kehidupan Sasya. Subjek wayang dalam lukisannya ditampilkan dengan gerak tangan yang disesuaikan dengan tema yang akan dipilihnya. Wayang golek seakan memiliki ekspresi yang beragam. Kekhasan lainnya adalah wayang golek dengan beragam kain batik yang merupakan hasil kreativitas Sasya dengan mengembangkan motif tradisi.

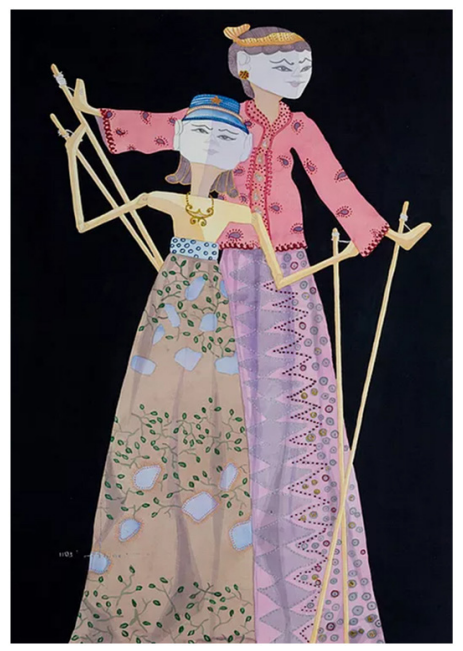

Gambar 2. Sasya Tranggono, My Son \& I, 113 x $80 \mathrm{~cm}, 2011$

Sumber: https://www.sasyatranggonostudio.com/

Pada periode berikutnya dari penggunaan wayanggolek, Sasya mencobamengekspresikan spiritualitas dalam lukisannya. Salah satunya karya berjudul Last Supper\#2. Jika pada lukisan aslinya yang ditampilkan adalah sosok manusia, maka dalam karya Sasya, tokohnya 
berganti menjadi sosok-sosok wayang kulit. Ia hanya mempertahankan sosok yang kemudian diidentifikasikan sebagai Yesus.

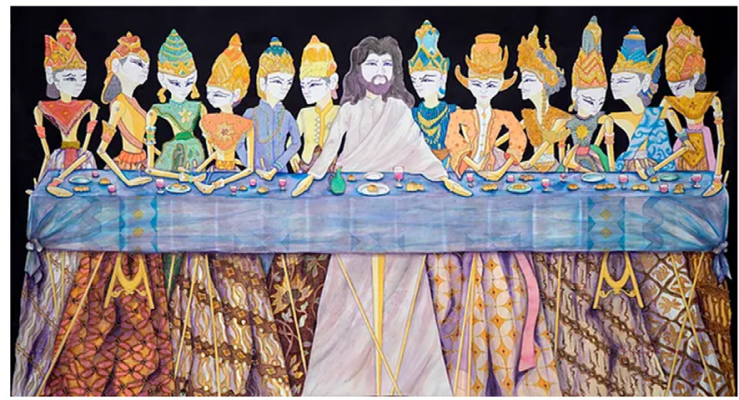

Gambar 3. Sasya Tranggono, Last Supper \#2

Sumber: https://www.sasyatranggonostudio.com/

Periode berikutnya Sasya membuat keragaman material dengan menggunakan batu-batu untuk memperkuat bentuk yang akan divisualisasikannya. Bentuk yang dominan dalam periode ini adalah kupu-kupu. Dia memadukan batu-batu seakan menjadi cat dalam lukisannya.
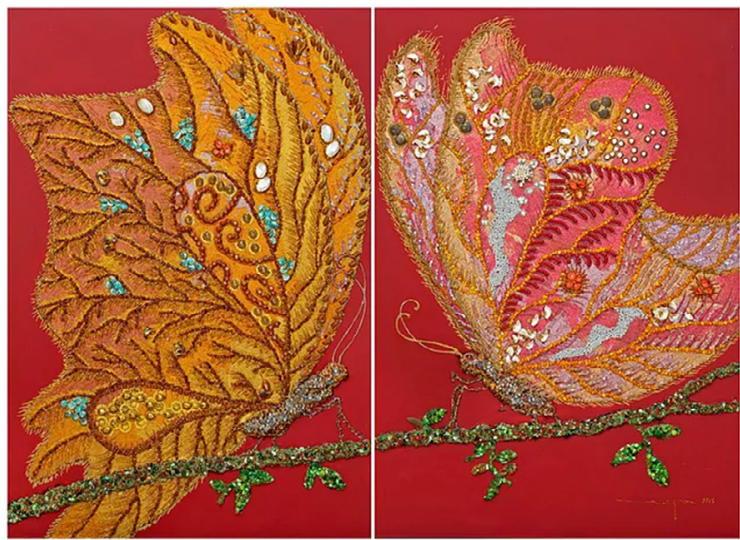

Gambar 4. Sasya Tranggono, Be Still and Know That I am GOD, Diptyque,120x180cm ,2015

Sumber: https://www.sasyatranggonostudio.com/

Sasya telah melalui tiga periode utama dalam pemilihan subjectmatter serta keragaman material, tetapi ia masih tetap menggunakan subjectmatter sebelumnya dalam berkarya. Karya-karya bunga dengan media cat air di atas kertas masih terus dilakukan. Demikian pula bentuk-bentuk wayang masih menjadi bagian dari karyanya. Pilhannya bergantung dari emosi yang akan diungkapkannya.
Pada tahun 2018 ia meluncurkan buku biografinya berjudul Faith. Buku tersebut menjadi penanda tiga puluh tahun perjalanan kariernya di dunia seni rupa. Penulis buku Faith adalah Jean Couteau seorang penulis seni rupa yang tinggal di Bali.

Melalui buku tersebut dipaparkan perjalanan hidup Sasya Tranggono sebagai putri dari pasangan dokter yang menjadi pemilik perusahaan kosmetik Ristra. Pembahasan lain difokuskan pada proses kreasi dan karya-karya Sasya dari satu period ke periode lainnya.

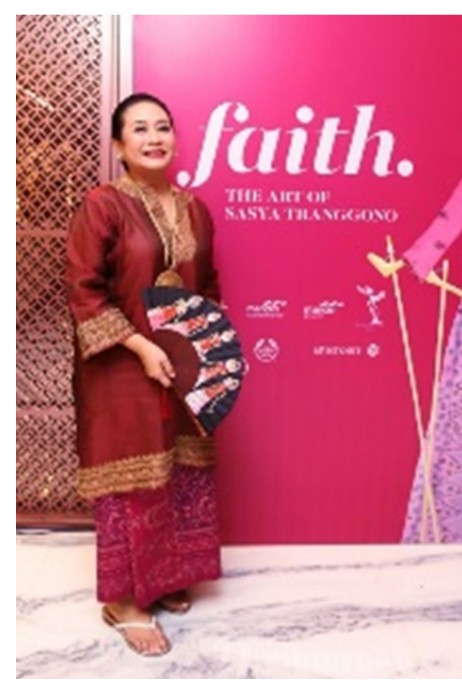

Gambar 5. Peluncuran Buku Biografi

Sasya Tranggono berjudul "Faith"

Sumber: https://www.tribunnews.com/images/editorial/ view/1780919/peluncuran-buku-faith-the-art-of-sasya-

tranggono

Berdasarkan pemaparan di atas dapat diketahui jika perjalanan karier Sasya Tranggono telah mencapai puncak aktualisasi diri. Hal ini tampak dari konsistensi berkarya, rentang waktu berkesenian, maupun kiprahnya alam berpameran tunggal di berbagai negara. Meskipun ia telah sampai di titik aktualisasi dirinya, tetapi posisi tersebut perlu dipertahankan dengan berbagai aktifitas yang dapat menjadi media publikasi dirinya. Selama masa pandemik ini berbagai kegiatan Sasya 
dalam mengaktualsiasikan dirinya menjadi sumber untuk menganalisis strateginya.

\section{ANALISIS STRATEGI AKTUALISASI DIRI SASYA TRANGGONO DALAM PANDEMIC COVID-19}

Berdasarkan teori ABRAHAM MASLOW yang dikonversikan untuk analisis proses aktualisasi diri perempuan perupa, maka dalam posisi Sasya Tranggono dia telah cukup dikenal dalam medan sosial seni rupa Indonesia. Dia masih harus mempertahankan dan meningkatkan diri untuk Kembali di puncak aktualisasi dirinya. Artinya secara skill dia telah mencapai puncak, dari segi kreativitas untuk mencapai originalitas dia masih harus memicu daya imajinasi dan nalarnya agar tetap berada di jajaran perempuan perupa Indonesia. Tema yang dipilihnya cenderung tema-tema personal walaupun dia memilih tema spiritual dalam karya wayangnya, tetapi masih unsur tema personal yang lebih menjadi karakteristiknya.

Sisi lain yang masih dapat dioptimalkan adalah pengolahan medium yang dipilihnya terutama Ketika ia mengembangkan penggunaan batu-batuan dalam periode karya kupu-kupunya. Dia masih dapat memadukan batu-batu tersebut dengan bidang kanvas yang tidak datar melainkan digabungkan dengan material lain yang memberikan kesan kasar. Misalnya ia padukan dengan kain. Hal itu menunjukkan untuk mencapai puncak aktualisasi diri perempuan perupa harus selalu mengembangkan kreativitasnya dan motivasi untuk memperlihatkan ciri khas atau originalitas dalam berkarya.

Konsep diri dalam diri Sasya Tranggono telah terbentuk sejak ia memutuskan untuk menjadi seorang seniman dibandingkan menjadi pengusaha. Ia berjuang untuk mempelajari teknik dalam seni rupa khususnya seni lukis.
Kemudian dia memutuskan berkarya dengan teknik cat air, serta menampilkan pilihan visual yang feminine melalui bunga dan kupu-kupu. Dalam periode kedua dia memilih subjectmatter lain yang merupakan metafora dari manusia yaitu wayang golek. Visualisasi baru dari tema wayangnya menjadi salah satu potensi untuk kemudian memperkokoh ideolectnya. Tema wayang masih dapat dikembangkan melalui pergantian sudut pandang dalam memvisualisasikan karya-karyanya.

Dalam periode ini sebenarnya terlihat bagaimana dia memadukan kelembutan dan kekerasan atau perjuangan yang harus ia jalani dalam kehidupan ini. Semua komposisi yang terlihat adalah keharmonisan, hal itu sejalan dengan pandangan hidupnya yang senantiasa memilih kedamaian dan berserah diri kepada Tuhan.

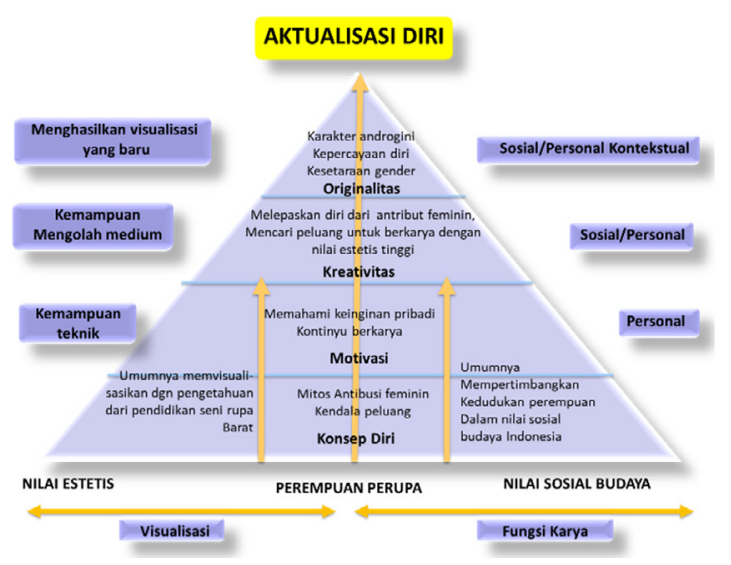

Gambar 6. Bagan Aktualisasi Diri Abraham Maslow yang Dikonversikan bagi Proses Aktualisasi Diri Perempuan Perupa Sumber: Adriati, 2010

diri, Sasya perlu memperhatikan medan sosial seni rupa dalam memandang karya-karyanya. Dalam situasi pandemic saat ini, dia perlu mempublikasikan diri melalui media digital. Mengingatkan kembali medan sosial seni khususnya apresiator yang berpotensi untuk menjadi kolektornya tentang karya-karya yang divisualiasikan olehnya. 
Di bawah ini merupakan pemikiran Van Maneen berkaitan dengan penyelenggaraan sebuah kegiatan seni perlu mempertimbangkan ketiga aspek utama yang berkaitan dengan konten (what); kemudian siapa yang akan berpameran dan audience yang akan hadir (who); serta bagaimana kegiatan tersebut berlangsung menyangkut ruang, waktu, orang-orang yang terlibat, dan hal-hal pelayanan lain yang dibutuhkan dalam sebuah kegiatan estetik (bow). Dipaparkan dalam gambar di bawah ini.

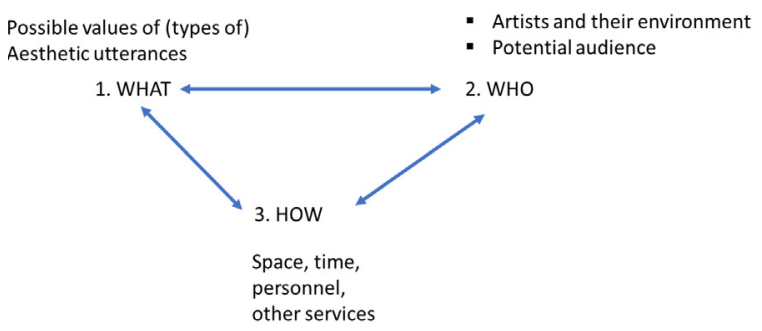

Gambar 7. Koordinat dari Tipe-tipe Kegiatan Estetik Sumber: Van Maneen, 2009

Berkaitan dalam situasi pandemik, ketiga faktor tersebut dapat dibuat dalam ruang digital. Kegiatan pameran selama pandemic covid-19 dilakukan secara virtual. Seniman membuat ruang pamer secara digital dengan memamerkan karya-karya dua dimensi maupun tiga dimensi yang dilihat secara virtual.

Sasya dalam situasi pandemic ini memanfaatkan media sosial seperti Instagram dan web site dalam mempublikasikan karyakaryanya. Ia memiliki Instagram personal @ sasyatranggono dan Instagram yang berkaitan dengan karyanya@sasyatranggonostudio yang dikelola oleh Sasyita Heritage Team. Di samping itu dia masih aktif mengikuti pameran Oppo Art Jakarta Virtual 2020 dengan bergabung dalam manajemen Puriartgallery. Pameran virtual itu berlangsung pada tanggal
19 Oktober - 15 Desember 2020 diikuti38 Gallery.

Melalui teori Van Maneen, Sasya telah berusaha untuk menentukan What yang mencakup karya mana dan nilai estetis karya seperti apa yang kemudian akan dipamerkan. Dia telah menentukan ketiga tipe karyanya yaitu wayang, bunga, dan kupu-kupu digabungkan dalam satu judul Faith Hope Love Series. Selanjutnya dia menentukan audience yang potensial untuk mengoleksi karyanya (Who), terakhir ia memamerkan secara virtual dalam Oppo Art Jakearta Virtual 2020 di bawah manajerial Puri art gallery. Berdasarkan penuturan tersebut, Sasya telah berusaha mengoptimalkan kekuatan estetis karyanya, memilih audiens dan mengajak audiens untuk melihat, menikmati dan memiliki karya-karyanya. Selanjutnya dia menentukan bekerjasama dengan sebuah galeri yang professional.

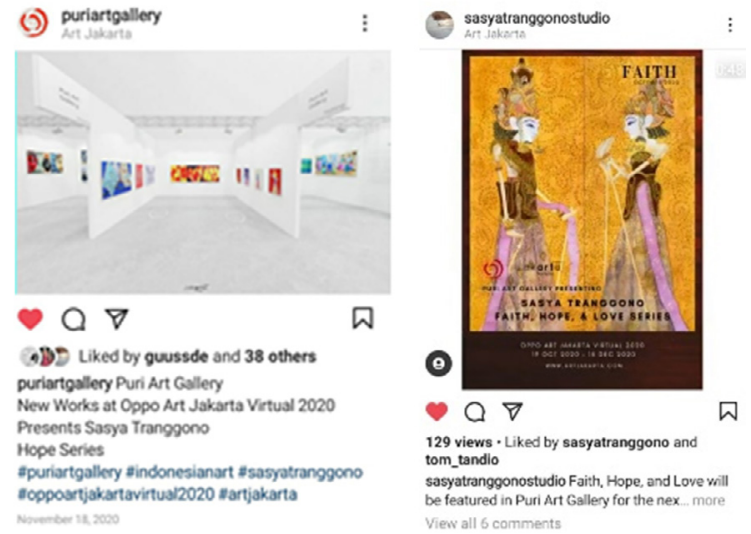

Gambar 8. IG Puriartgallery dan IG Sasyatranggonostudio yang memperlihatkan Pameran Oppo Art Jakarta Virtual 2020

Proses publikasi pameran tersebut sangat gencar dilakukan dalam IG @puriartgallery maupun IG studio dan personal Sasya Tranggono. Di samping itu agar masyarakat paham tentang karya-karyanya, pihak puriartgallery dan Sasya Tranggono mengadakan kegiatan IG live yang selanjutnya dapat dilihat dalam IG TV. Tayangan tersebut dapat 
dilihat kapanpun oleh audiens yang ingin mengetahui lebih mendalam tentang karyakarya Sasyatranggono.

Di samping pameran secara virtual, Sasya Tranggono menjadi pembicara untuk beberapa webinar atau seminar online. Salah satunya webinar berkaitan dengan mengangkat batik Indonesia dalam meningkatkan perekonomian masyarakat Indonesia. Seminar online tersebut berlangsung pada tanggal 26 November 2020 .

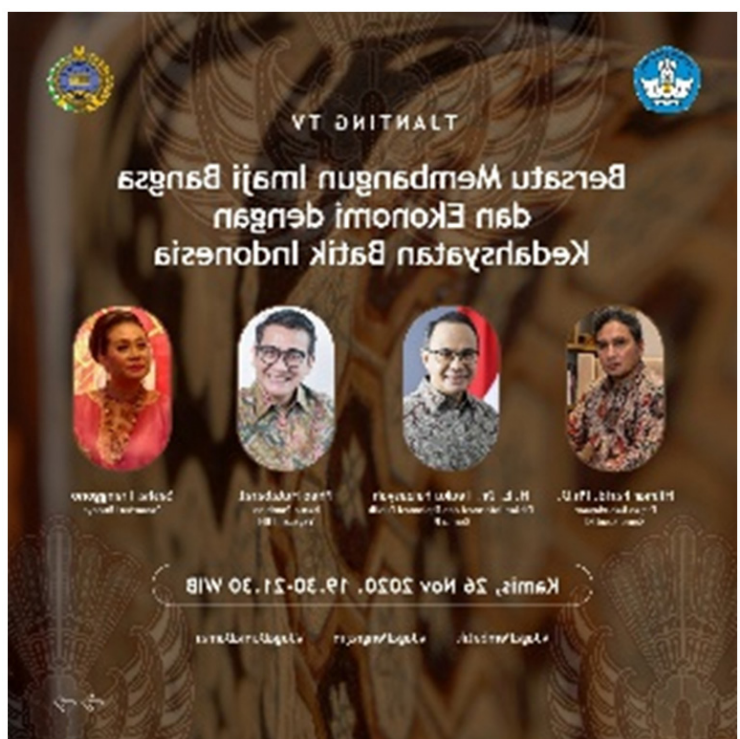

Gambar 9. Poster Kegiatan Sasya Tranggono sebagai Pembicara.

Berdasarkan teori building your personal brand in the age of social media dari Brittany Hennessy, IG (Instagram) seseorang haruslah menarik secara visual. Follower hanya akan melihat jika tampilan dari IG seseorang menarik visualnya. Visual yang menarik berdasarkan teori Hennessy salah satunya dari foto yang dipilih untuk profile, kejelasan identitas. Selanjutnya foto-foto yang ditampilkan oleh pemilik akun IG tersebut.

Sasya Tranggono dalam IG Sasyatranggonostudio berusaha memenuhi kreteria di atas dengan memberikan foto profile dan penjelasan pemilik akun. Isi dari IG karya-karya tersebut pada masa pandemic digunakan oleh Sasya sebagai media untuk menginformasikan perjalanan karier dan karya-karyanya. Hanya saja masih belum banyak followers dari IG tersebut yang aktif memberikan "like" untuk setiap posting foto atau kegiatan Sasya Tranggono. Hal tersebut perlu menjadi pertimbangan dari seniman untuk membuat akunnya menarik dan diminati.

Setelah kegiatan pameran secara virtual, Sasya Tranggono yang selama pandemic tinggal di Singapore, menyelenggarakan pameran di Yang Gallery Singapore Pada tanggal 12 Maret - 23 April 2021. Dalam pameran tersebut ia menampilkan lukisan-lukisan wayang terbarunya serta karya-karya lainnya.

Dalam publikasi terlihat jumlah like dari IG yanggallery sangat banyak sejumlah 1618. Berbeda dengan like di IG Sasyatranggono pribadi hanya 52 likes. Kemungkinan besar rekan sejawat Sasyatranggono tidak banyak yang menggunakan sosial media Instagram. Sasyatranggono studio perlu menarik minat kaum millennial untuk mau membuka IG tersebut sehingga semakin banyak orang yang mengenal karya-karya Sassyatranggono.
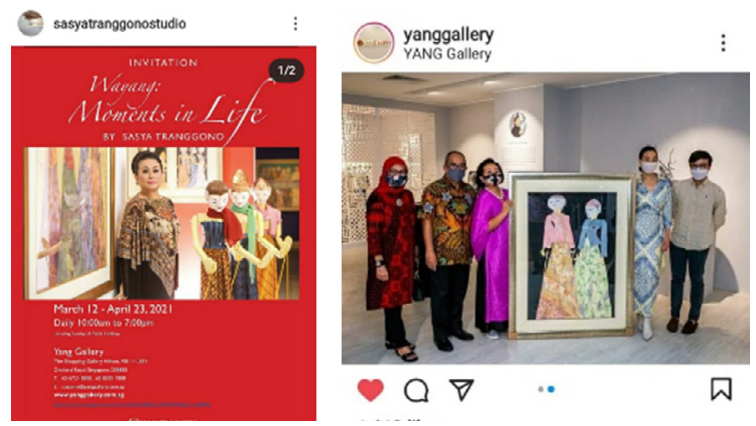

Gambar 10. Publikasi Pameran Tunggal Sasya di Yang Gallery Singapore.

\section{KESIMPULAN}

Pemaparan di atas menunjukkan jika Sasya Tranggono berusaha untuk dapat mengaktualisasikan dirinya melalui karya-karya yang 
dia visualisasikan. Media sosial yang digunakan terdiri dari Instagram, website, serta pameran secara luring.

Teknik mempublikasikan karya dengan media daring seperti dalam Instagram miliknya masih belum banyak yang membuka. Instagram dari media parthernya yaitu gallery tempat Sasya berpameranlah yang memberikan kontribusi proses aktualisasi diri Sasya lewat karyanya. Dalam mendukung kegiatan pamerannya, Sasya dan media parther menyelenggarakan kegiatan diskusi seni rupa. Melalui kegiatan tersebut Sasya berusaha memperkenalkan nilai estetis karyanya sehingga semakin banyak orang yang paham dan tertarik untuk mengapresiasi karyanya. Sepanjang pandemic covid-19 ini Sasya telah melakukan berbagai aktifitas agar karya-karyanya dapat dikenal masyarakat secara luas.

\section{DAFTAR PUSTAKA}

ADRIATI, I.

2010. Analisis Proses Aktualisasi Diri

Perempuan Perupa Indonesia,

Disertasi, Institut teknologi Bandung.

Coutteau, J.

2018. Faith: The Art of Sasya Tranggono, Afterhours Books, Jakarta.

\section{HeNNESSY, B.}

2018. Influencer, Kensington books, New York.

\section{MAANEN, $\mathrm{H}$.}

2009. How To Study Art World, Amsterdam University Press, Amsterdam.

\section{Ucapan Terima Kasih}

BP-PTNBH Kemerinstek 2020 yang telah memberikan dana riset. 